\title{
Sinopse do gênero Acalypha L. (Euphorbiaceae) no Estado de São Paulo, Brasil
}

\author{
Ana Angélica Cordeiro de Sousa ${ }^{1,3,4}$, Inês Cordeiro ${ }^{1}$, José Maria Cardiel $^{2}$ and Maria Beatriz Rossi Caruzo ${ }^{1,3}$
}

Recebido: 18.09.2016; aceito: 4.05.2017

\begin{abstract}
Synopsis of the genus Acalypha L. (Euphorbiaceae) in the State of São Paulo, Brazil). Euphorbiaceae is one of the largest families of angiosperms, with 246 genera and approximately 6300 species distributed worldwide. Acalypha is the third largest genus of this family, including about 450 species and with a pantropical distribution. This work was based on the analysis of herbarium collections aiming to carry out the survey of species of the genus Acalypha in the State of São Paulo, as well as contribute to the knowledge of the family in the region and provide an identification key for the species of the genus. We recognized 14 species of Acalypha for São Paulo State, of which two represent new for the State records (A. herzogiana and A. velamea).
\end{abstract}

Keywords: Brazilian flora, taxonomy

RESUMO - (Sinopse do gênero Acalypha L. (Euphorbiaceae) no Estado de São Paulo, Brasil). Euphorbiaceae é uma das maiores famílias de Angiospermas, com 246 gêneros e aproximadamente 6.300 espécies distribuídas em todas as regiões do mundo. Acalypha é o terceiro maior gênero da família com cerca de 450 espécies e possui distribuição pantropical. Este trabalho foi baseado na análise de coleções de herbários e visou realizar o levantamento de espécies do gênero Acalypha no Estado de São Paulo, contribuir para o conhecimento da família na região, além de produzir uma chave de identificação para as espécies do gênero. Foram reconhecidas 14 espécies de Acalypha em São Paulo, sendo duas novas ocorrências para o Estado (A. velamea e A. herzogiana).

Palavras-chave: Flora do Brasil, taxonomia

\section{Introdução}

Euphorbiaceae é uma das maiores e mais diversas famílias das angiospermas (Govaerts et al. 2000, Radcliffe-Smith 2001), sendo a maior dentro da ordem Malpighiales (Wurdack \& Davis 2009). A família conta com 246 gêneros e aproximadamente 6.300 espécies (Wurdack et al. 2005) distribuídas em todo o mundo, principalmente nas regiões tropicais (Govaerts et al. 2000).

Segundo BFG (2015), Euphorbiaceae está entre as 10 famílias de Angiospermas mais diversas da flora brasileira, com 934 espécies reconhecidas no país. No Estado de São Paulo ocorrem 36 gêneros e 154 espécies da família (Wanderley et al. 2011).

Acalypha foi descrito na clássica obra de Carl Von Linnaeus (1753), Species Plantarum, com base em três espécies: Acalypha indica L., A. virginica L. e A. australis L. Müller Argoviensis, na obra Flora Brasiliensis (1874), listou trinta e seis espécies do gênero para o Brasil. A última revisão mais ampla sobre o gênero foi realizada por Ferdinand Pax e Käthe Hoffmann no Das Pflanzenreich de Adolf Engler (1924), onde foram estabelecidos três subgêneros: Linostachys, Euacalypha e Androcephala. Desde então, pouca atenção tem sido atribuída ao gênero (Cardiel \& Muñoz-Rodríguez 2012a), que dentre os gêneros de Euphorbiaceae é um dos mais expressivos, sendo antecedido somente por Croton e Euphorbia. Tratamentos florísticos para o gênero vêm sendo produzidos na América do Sul, com a inclusão de novos taxa e atualizações taxonômicas infragenéricas (p.e. Cardiel 1994, Cardiel 1995a, Cardiel 1995b, Cardiel \& Muñoz-Rodríguez 2012a, Cardiel \& MuñozRodríguez 2012b, Cardiel \& Muñoz-Rodríguez 2013,

1. Instituto de Botânica, Núcleo de Pesquisa Curadoria do Herbário, caixa postal 68045, 01061-970 São Paulo, SP, Brasil

2. Universidade Autónoma de Madrid, Faculdade de Ciências, Departamento de Biología, Unidade de Botânica, 28049 Madrid, Espanha

3. Universidade Federal de São Paulo, Departamento de Ecologia e Biologia Evolutiva, 09972-270 Diadema, SP, Brasil

4. Autor para correspondência: ana_angelcs@hotmail.com 
Cardiel \& Muñoz-Rodríguez 2015, Cardiel et al. 2014, Carneiro et al. 2002, Cordeiro 2004).

Estudos filogenéticos preliminares evidenciaram o monofiletismo de Acalypha, porém reconheceram apenas dois subgêneros: Linostachys e Acalypha (Sagun et al. 2010, Levin et al. 2005). Ainda assim, Acalypha necessita de uma ampla revisão para definir os limites do gênero e estabelecer uma classificação infragenérica condizente com a história evolutiva do grupo.

Acalypha é o terceiro maior gênero de Euphorbiaceae, com cerca de 450 espécies, e possui distribuição pantropical (Webster 1994, RadcliffeSmith 2001), sendo as Américas uma região com alto grau de endemismo. Os seus principais centros de diversidade estão localizados no México, Bolivia e Peru (Gordillo et al. 2002, Cardiel \& MuñozRodríguez 2013). Espécies de Acalypha podem ser ervas, arbustos ou árvores, ocorrem nos mais variados habitats, podendo ser encontradas desde florestas tropicais a regiões semiáridas, do nível do mar até 4000 metros de altitude (Cardiel \& Muñoz-Rodríguez 2012a).

No Brasil, o gênero está representado por aproximadamente 50 espécies, sendo 30 endêmicas, distribuídas por todas as regiões do país e presentes nos domínios fitogeográficos da Amazônia, Cerrado, Floresta Atlântica, Pampa e Caatinga (Cardiel 2015). Para o Estado de São Paulo, Wanderley et al. (2011) listaram 12 espécies de Acalypha e na Flora do Brasil são reconhecidas 13 espécies (Cardiel 2015). Este trabalho teve como objetivo contribuir para o conhecimento da diversidade vegetal do Estado de São Paulo, com enfoque em Acalypha.

\section{Material e métodos}

A área de estudo foi o Estado de São Paulo, localizado na região Sudeste do país, com altitude de 0 à $1.200 \mathrm{~m}$. O Estado tem como limites os Estados de Minas Gerais ao norte e nordeste, Paraná ao sul, Rio de Janeiro a leste e Mato Grosso do Sul a oeste, além do Oceano Atlântico a sudeste, e sua área total é $248.209,426 \mathrm{~km}^{2}$. Está localizado em uma região com clima tropical à tropical úmido e composição florística bastante diversa, podendo ser encontrados desde Florestas Ombrófilas Densas Montana até fisionomias de Cerrado (Wanderley et al. 2009).

O trabalho foi baseado na análise das coleções depositadas, principalmente, no Herbário do Instituto de Botânica de São Paulo (SP). Também foram analisadas as coleções depositadas nos seguintes herbários: B, BM, BOTU, C, ESA, G, G-DC, K, MAUAM, MO, NY, P, R, RB, S, SPF SPSF e W (siglas de acordo com Thiers, continuamente atualizado). Foram realizadas duas expedições de campo (nos municípios de Águas da Prata e São Paulo), onde foi possível encontrar três das espécies citadas no trabalho: Acalypha amblyodonta (Müll.Arg.) Müll. Arg., Acalypha gracilis Spreng. e Acalypha poiretii Spreng. Neste trabalho foram reconhecidos apenas os taxa nativos do Estado.

A descrição do gênero foi baseada em bibliografia especializada e tem um caráter mais amplo, ou seja, não é baseada apenas nas espécies de São Paulo. Para cada espécie são referidas: publicação original, coleções-tipo, basiônimo (quando existente), nomes populares retirados dos rótulos de herbários (quando existentes) ou da literatura, distribuição geográfica, tipo de vegetação de ocorrência e um material selecionado (foi escolhido o material que melhor representava, morfologicamente, a espécie). Quando necessário, foi citado um material adicional, utilizado para uma melhor delimitação da espécie.

Foram analisadas imagens digitais das coleçõestipo depositadas nos principais herbários internacionais, disponíveis no JSTOR Global Plants (http://plants. jstor.org/), para melhor delimitação das espécies estudadas. Essas imagens, quando observadas, estão seguidas de "!" no cabeçalho das espécies.

\section{Resultados e Discussão}

Foram encontradas 14 espécies de Acalypha para São Paulo, as quais ocorrem nos diversos tipos de vegetação ocorrentes no Estado. Das 14 espécies reconhecidas neste trabalho, 10 já constavam no checklist das Spermatophyta do Estado de São Paulo (Wanderley et al. 2011). No entanto, das 13 espécies citadas para São Paulo na Lista de Espécies da Flora do Brasil (Cardiel 2015), duas não foram reconhecidas nesse trabalho (Acalypha martiana Müll.Arg. e Acalypha urostachya Baill. pois coleções identificadas com estes nomes eram, na realidade, A. gracilis Spreng.) e duas novas ocorrências foram indicadas para o estado, A. herzogiana Pax \& K. Hoffm. e Acalypha velamea Baill.

$\mathrm{Na}$ área de estudo são amplamente cultivadas como ornamentais: Acalypha hispida Burm.f., e $A$. wilkesiana Müll.Arg., espécies exóticas originárias da Índia e Oceania, respectivamente. Além delas, é bastante popular como forração a "rabo-de-gato", 
um cultivar de $A$. herzogiana, equivocadamente reconhecida como $A$. reptans $\mathrm{Sw}$, como foi recentemente esclarecido por Steinmann \& Levin (2011). Acalypha reptans, na verdade, é uma espécie nativa das Antilhas, que não é normalmente cultivada; as duas se diferenciam pela forma de crescimento, posição e tipo da inflorescência pistilada e ramificação e coloração dos estiletes. Não foram encontrados registros de ocorrência espontânea ou subespontânea dessas espécies na área de estudo.

Acalypha L. Sp. P1. 2: 1003 (1753).

Árvores, arbustos ou ervas, perenes ou anuais, monoicos, raramente dioicos. Indumento de tricomas simples, glandulares ou estrelados. Folhas alternas, inteiras, geralmente pecioladas, 2(1)-estipulada, estípulas laterais, persistentes ou caducas; lâmina foliar geralmente crenado-denteada ou serreada, peninérvia ou palmatinérvia. Inflorescências axilares ou terminais, unissexuais ou bissexuais. Inflorescência estaminada espiciforme, multiflora, flores subtendidas por bráctea diminuta. Inflorescência pistilada geralmente espiciforme, às vezes racemosa ou paniculada; flores subentendidas por brácteas geralmente conspícuas, acrescentes ou não no fruto, geralmente denteadas ou lobadas. Inflorescências bissexuais espiciformes com flores estaminadas no ápice e pistiladas na base. Flores unissexuais, monoclamídeas, disco ausente. Flores estaminadas pequenas, curtamente pediceladas, globosas no botão, prefloração valvar; cálice 4-partido; estames 4-8(-16), livres ou conados na base; anteras divaricadas ou com tecas pêndulas, vermiformes após a antese; grãos de pólen oblatoesferoidal, 3-5 pseudoporado. Flores pistiladas sésseis ou subsésseis, raro pediceladas, prefloração imbricada; cálice 3-(4-5)-partido, inconspícuo, unido na base; ovário (1-2)3-carpelar, geralmente muricado ou papiloso, pubescente a glabrescente; estiletes geralmente avermelhados, livres ou conados na base, profundamente laciniados em segmentos filiformes, raramente bífidos ou inteiros. Fruto cápsula de deiscência septicida, geralmente envolvido pela bráctea acrescente. Sementes ovoides a elipsoides, carunculadas ou não, lisas ou foveoladas, endosperma presente, branco. (Müller Argoviensis 1874, Pax \& Hoffmann 1924, Radcliffe-Smith 2001).

\section{Chave para as espécies de Acalypha L. ocorrentes no Estado de São Paulo}

1. Flores pistiladas pediceladas, cálice 5-partido. Brácteas pistiladas não acrescentes no fruto A. villosa

1. Flores pistiladas sésseis, cálice 3-partido. Brácteas pistiladas acrescente ao fruto

2. Plantas herbáceas a subarbustivas. Inflorescências pistiladas axilares ou flores pistiladas solitárias, axilares, com brácteas menores que nas inflorescências

A. herzogiana

2. Plantas subarbustivas, arbustivas ou arbóreas. Flores pistiladas exclusivamente em inflorescências terminais, com brácteas bem desenvolvidas

3. Plantas dioicas, subarbustivas. Estiletes pouco laciniados

A. claussenii

3. Plantas monoicas, arbustivas ou arbóreas. Estiletes muito laciniados

4. Inflorescências exclusivamente unissexuais (em A. communis as inflorescências são falsamente unissexuais, uma vez que as flores masculinas das raras inflorescências bissexuais são cedo caducas)

5. Inflorescências pistiladas terminais e estaminadas axilares, raramente terminais

6. Folhas sésseis a subsésseis; pecíolo nunca maior que $0,5 \mathrm{~cm}$ de comprimento. Inflorescências estaminadas nunca terminais A. velamea

6. Folhas pecioladas; pecíolos sempre maiores que $0,5 \mathrm{~cm}$ de comprimento. Inflorescência terminal falsamente unissexual, com porção terminal estaminada caduca raramente terminais .

A. communis

5. Inflorescências pistiladas axilares

7. Margem foliar inteira a levemente crenada. Inflorescências pistiladas subterminais.

Bráctea da flor pistilada com tricomas glandulares na margem . A. digynostachya

7. Margem foliar dentada ou serreada. Inflorescência pistiladas axilares. Bráctea da flor pistilada sem tricomas glandulares na margem

8. Folhas lanceoladas. Bráctea da flor pistilada profundamente laciniada .... A. gracilis 8. Folhas largamente ovadas a oblongas. Bráctea da flor pistilada rasamente dentada A. macrostachya 
4. Inflorescências bissexuais e unissexuais na mesma planta ou somente inflorescências bissexuais

9. Inflorescências bissexuais e unissexuais na mesma planta

10. Folhas romboidais a elípticas. Inflorescências terminais e axilares A. poiretii

10. Folhas lanceoladas. Inflorescências somente axilares A. diversifolia

9. Inflorescências somente bissexuais

11. Sistema subterrâneo muito desenvolvido (rizomatoso); plantas muito ramificadas. Inflorescências conspicuamente pedunculadas (pedúnculo maior que $0,5 \mathrm{~cm}$ ) A. multicaulis

11. Sistema subterrâneo não desenvolvido; plantas pouco ramificadas. Inflorescências sésseis ou inconspicuamente pedunculadas (pedúnculo menor que $0,5 \mathrm{~cm}$ )

12. Brácteas das flores pistiladas triangular-ovais, com margens ciliado-glandulosas; 1 flor pistilada por bráctea A. brasiliensis

12. Brácteas das flores pistiladas orbiculares ou reniformes, margens não ciliadoglandulosas; 2-3 flores pistiladas por bráctea

13. Folhas com tricomas filiformes. Inflorescências sésseis; brácteas pistiladas orbiculares, 3 flores por bráctea A. amblyodonta

13. Folhas com diminutos tricomas estrelados. Inflorescências inconspicuamente pedunculadas; brácteas pistiladas reniformes, 2 flores por bráctea A. accedens

Acalypha accedens Müll.Arg. Linnaea 34: 35. 1865. Tipo: BRASIL. "In Brasilia meridionali", J. Lhotsky s.n. (holótipo G-DC [G00324475!]; isótipos G!, W!).

Acalypha accedens é uma espécie arbustiva, com tricomas estrelados diminutos em ramos jovens e folhas, posteriormente glabrescente; inflorescências com um pequeno espaço entre as subinflorescências pistiladas na base e as estaminadas no ápice; bráctea da flor pistilada reniforme com diminutas glândulas no ápice dos dentes; ovário com indumento hirto e estiletes bastante ramificados desde a base.

A espécie ésemelhante morfologicamentea Acalypha brasiliensis, principalmente pela presença de inflorescências bissexuais. No entanto, A. accedens folhas curtamente pecioladas (pecíolos até $6 \mathrm{~cm}$ de comprimento) e mais de uma flor por bráctea pistilada, enquanto $A$. brasiliensis possui folhas longamente pecioladas (maiores que $6 \mathrm{~cm}$ de comprimento) e sempre uma flor por bráctea pistilada.

É endêmica do Brasil, ocorrendo em quase toda a região Sudeste do país (MG, RJ e SP). É frequentemente encontrada em Floresta Atlântica, nas bordas de florestas ombrófilas.

Material selecionado: BRASIL. São PAULO: Mairiporã, 6-X-1997, I. Cordeiro 120 (SP).

Acalypha amblyodonta (Müll.Arg.) Müll.Arg. Fl. Bras. 11(2): 365.1874 E Acalypha cuspidata var. amblyodonta Müll.Arg. Linnaea 34: 37. 1866. Tipo: BRASIL. Rio DE JANEIRo: Rio de Janeiro, $C$. Gaudichaud-Beaupré 1134 (lectótipo $\mathrm{P}$ [P00635211!], designado por Cardiel et al. [2013b: 155]; isolectótipos $\mathrm{B} \uparrow$ [B neg. F 5277!], G-DC!).

Figura $1 \mathrm{a}-\mathrm{f}$
Acalypha amblyodonta é uma planta arbustiva, com brácteas das flores pistiladas orbiculares, com margem denteada, persistentes, acrescentes e bastante vistosas na frutificação. As inflorescências possuem um longo espaço entre as subinflorescências pistiladas dispostas na base, geralmente congestas, e as subinflorescências estaminadas mais laxamente dispostas no ápice da inflorescências. Assemelha-se a A. multicaulis, mas nunca é prostrada ou subereta e nem possui sistema subterrâneo bem desenvolvido como em $A$. multicaulis.

A espécie ocorre na Argentina, Bolivia, Brasil e Paraguai (Cardiel \& Muñoz-Rodríguez 2015). No Brasil, é encontrada nas regiões Nordeste (BA), Sudeste (MG, RJ e SP), Centro-Oeste (GO) e Sul (PR) em borda de florestas ombrófilas montanas.

Material selecionado: BRASIL. SÃo PAULO: Cunha, 18-XII-1996, J. P. Souza et al. 1040 (SP).

Acalypha brasiliensis Müll.Arg. Linnaea 34: 37. 1865. Tipo: BRASIL. BAHIA: Ponçod'Arcia, VI-1844, J. S. Blanchet 3865 (lectótipo G-DC [G00324483!], designado por Cardiel \& Muñoz-Rodríguez [2015: 390]; isolectótipos, G!, BM!, P!).

Figuras 1 g-h, 2 a-c

Acalypha brasiliensis é uma espécie arbustiva de pequeno porte, com diminutos tricomas estrelados em ramos jovens e folhas, similares aos de $A$. accedens, da qual se diferencia pela morfologia das inflorescências (ver comentários em A. accedens). A espécie pode ser reconhecida pelas folhas oval-elípticas longamente pecioladas e pelas brácteas das flores pistiladas ovaltriangulares, de margem denteada, com pequenas glândulas no ápice dos dentes. 

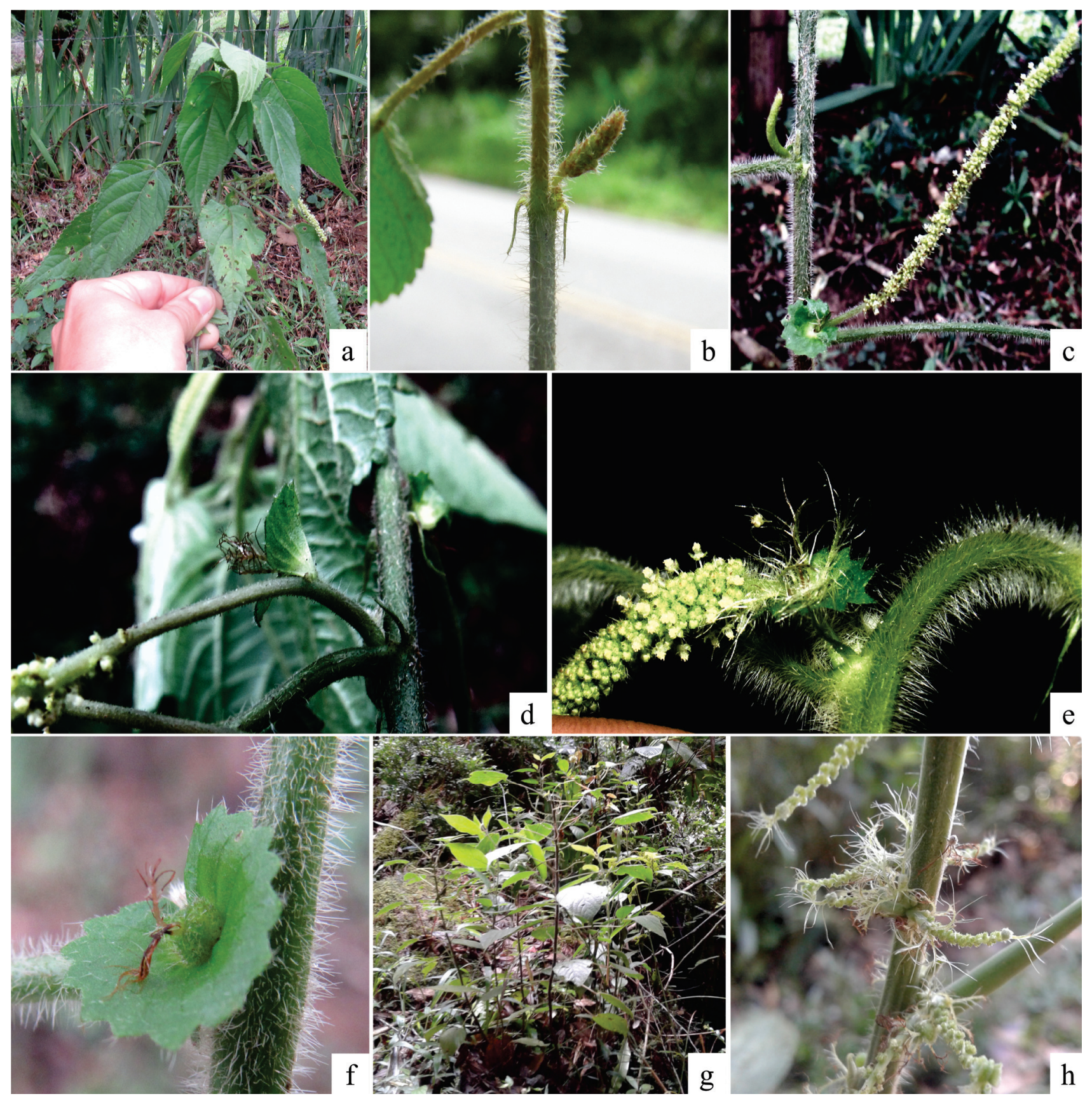

Figura 1. a-f. Acalypha amblyodonta. a. Hábito. b. Estípulas deflexas, tricomas filiformes e patentes nos ramos. c. Inflorescência bissexual. d. Detalhe da inflorescência evidenciando o pedúnculo. e. flores pistiladas e estaminadas. f. Fruto e bráctea acrescente. g-h. A. brasiliensis. g. Hábito. h. Inflorescência bissexual. Fotos: (a, b, c, d, f, g, h) A.A.C. Sousa; (e) O.L.M. Silva. Vouchers: (a-f) A.A.C. Sousa 25; (g-h) A.A.C. Sousa 10.

Figure 1. a-f. Acalypha amblyodonta. a. Habit. b. Deflexed stipules, filiform and patent trichomes on the branches. c. Bisexual inflorescence. d. Detail of the inflorescence showing the peduncle. e. Pistillate and staminate flowers. f. Fruit and accrescent bract. g-h. A. brasiliensis. g. Habit. h. Bisexual inflorescence. Photos: (a, b, c, d, f, g, h) A.A.C. Sousa, (e) O.L.M. Silva. Vouchers: (a, f) A.A.C. Sousa 25, (g, h) A.A.C. Sousa 10. 
Ocorre na Argentina e Brasil. No Brasil, Acalypha brasiliensis é distribuída em quase todas as regiões brasileiras: Centro-Oeste (GO), Nordeste (AL, BA, MA, PB), Norte (AM) e Sudeste (ES, MG, RJ e SP); encontrada em borda de florestas ombrófilas.

Em diversos herbários, coleções de Acalypha brasiliensis encontravam-se identificadas como $A$. communis. As duas espécies podem ser diferenciadas, principalmente, pelas inflorescências (axilares bissexuais em $A$. brasiliensis vs axilares unissexuais e terminais bissexuais em $A$. communis).

Material selecionado: BRASIL. S̃̃o PAULO: Socorro, Estrada dos Gabiroga, 19-V-1995, G.F. Árbocz 1416G (MAUAM, SP).

Acalypha claussenii (Turcz.) Müll.Arg. Linnaea 34: $51.1865 \equiv$ Odonteilema claussenii Turcz. Bull. Soc. Imp. Naturalistes Moscou 21(1): 588. 1848. Tipo: BRASIL. Minas GERAIS: P. Claussen 774, 775, 1458, s.n. (síntipos BM, G!, GH!, K, MO, P!, W).

Figura $2 \mathrm{~d}-\mathrm{e}$

Acalypha claussenii é uma espécie subarbustiva de pequeno porte, dioica, densamente pubescente e com sistema subterrâneo desenvolvido. Apresenta inflorescências pistiladas e estaminadas sempre terminais e os estiletes são longos e pouco ramificados e de coloração avermelhada, às vezes castanho-escuros no material herborizado. Acalypha claussenii difere-se das demais espécies ocorrentes em São Paulo por ser a única dioica.

A espécie é típica de vegetação de cerrado e é endêmica do Brasil, onde ocorre no Centro-Oeste (DF, GO e MT), Norte (TO) e Sudeste (MG e SP). No Estado de São Paulo, a espécie é conhecida apenas pela coleção de A. St.-Hilaire 1000.

Material selecionado: BRASIL. SÃo PAULO: 1816 a 1821. A. St-Hilaire C.1 1000 (P!).

Material adicional selecionado: BRASIL. Distrito FEDERAL: Reserva Ecológica do IBGE, M.L. Fonseca \& D. Alvarenga 2078 (SP).

Acalypha communis Müll.Arg. Linnaea 34: 23. 1865. Tipo: BRASIL. Minas GeraIs: J. F. Widgren s.n. (lectótipo S [S07-12617!], designado por Cardiel et al. [2013a: 1299]; isolectótipo BR [BR699782!]). Figuras 2 f, 3 a-f

Espécie subarbustiva a arbustiva, com indumento muito variável, frequentemente confundida com $A$. brasiliensis, principalmente pela semelhança com relação aos caracteres vegetativos das duas espécies. No entanto, A. communis pode ser diferenciada de $A$. brasiliensis por suas brácteas pistiladas (profundamente laciniadas em A. communis e dentadas em A. brasiliensis) e pelas inflorescências (bissexuais e unissexuais em $A$. communis e somente bissexuais em $A$. brasiliensis), dentre outras características.

Ocorre na Argentina, Brasil, Bolivia, Paraguai e Uruguay (Cardiel et al. 2013a). No Brasil é amplamente distribuída em todas as regiões: Norte (PA), Nordeste (MA), Centro-Oeste (DF, GO, MT e MS), Sudeste (MG, RJ e SP) e Sul (PR).

Acalypha communis é uma especie muito polimórfica, para a qual são descritas numerosas variedades e subespécies (Cardiel et al. 2013b). As coleções provenientes de São Paulo podem ser identificadas como A. communis subsp. communis. Pode ser encontrada tanto em bordas de florestas ombrófilas, floresta ciliar e também em campos com altitude superior $1.000 \mathrm{~m}$, crescendo entre rochas.

Material selecionado: BRASIL. São PAULO: São João da Boa Vista, 11-XII-1920, G. Gerht s.n. (SP 3519).

Acalypha digynostachya Baill. Adansonia 5: 233. 1865. Tipo: BRASIL. São PAULO: "bois vierges près de Lambari", A. St-Hilaire $C^{2} 1131$ (síntipos $\mathrm{P}$ [P00635238!], P [P00635240!], P [P00635239!]). Figuras 3 g-i, 4 a-b

Acalypha digynostachya é uma espécie arbustiva, glabrescente, com caules decumbentes e folhas com nervura central proeminente. As inflorescências são sempre axilares, as estaminadas ocorrem na parte mais basal dos ramos, enquanto as pistiladas na porção terminal. A margem inteira, inconspicuamente serrilhada a levemente crenada do limbo distingue esta espécie das demais ocorrentes em São Paulo, que apresentam margens variavelmente denteadas. A espécie é semelhante a A. gracilis, da qual difere pelo seu indumento (pubescente $A$. gracilis vs glabrescente em A. digynostachya) e margem foliar (dentada em $A$. gracilis vs margem inteira a levemente crenada em $A$. digynostachya).

É uma espécie típica da Floresta Atlântica, ocorrendo no interior de florestas estacionais semidecíduas. Espécie encontra-se distribuída nas regiões Sudeste (ES, MG, RJ e SP) e Sul (PR) do Brasil.

Material selecionado: BRASIL. S̃̃o PAULO: Eldorado, 22-III-2005, J.E. Meireles et al. 181 (SP). 

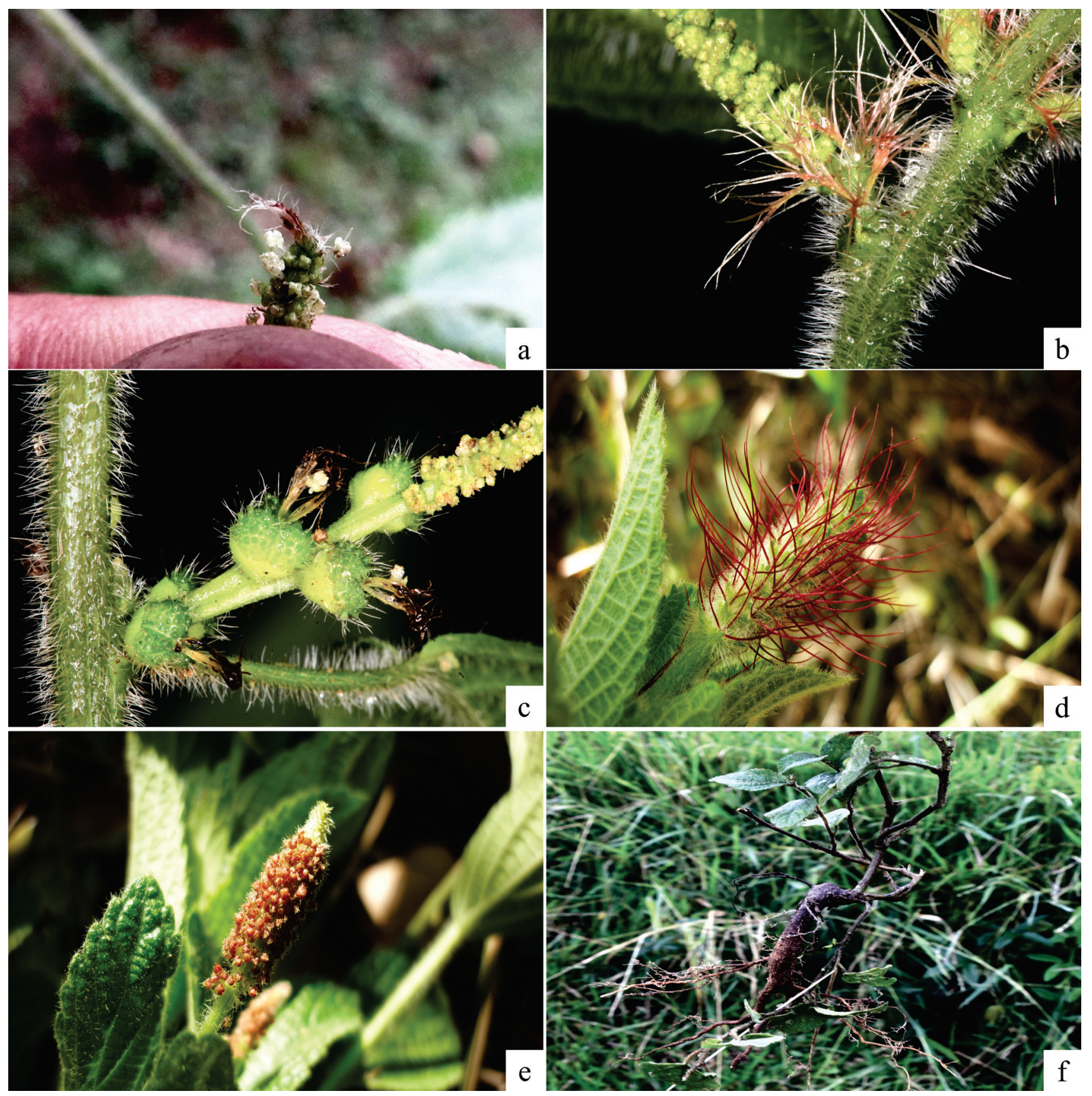

Figura 2. a-c. Acalypha brasiliensis. a. Detalhe da inflorescência estaminada com uma flor alomórfica no ápice. b. Detalhe do ramo com uma flor feminina, destacando o indumento de tricomas filiformes, patentes. c. Frutos e bráctea acrescente. d-e. A. claussenii. d. Inflorescência pistilada. e. inflorescência estaminada. f. A. communis. f. Planta com sistema subterrâneo exposto. Fotos: (a) A.A.C. Sousa; (b, c, f) O.L.M. Silva; (d, e) R. Sartin. Vouchers: (a, c) A.A.C. Sousa 20; (d,e) sem coleta; (f) A.A.C. Sousa 15.

Figure 2. a-c. Acalypha brasiliensis. a. Detail of the staminate inflorescence with an allomorphic flower at the apex b. Detail of the branch with a pistillate flower, showing the indument of filiform and patents trichomes. c. Fruits and accrescent bract. d-e. A. claussenii. d. Pistillate inflorescence. e. Staminate inflorescence. f. A. communis. f. Plant with exposed underground system. Photos: (a) A.A.C.Sousa; (b, c, f) O.L.M. Silva; (d,e) R. Sartin. Vouchers: (a, c) A.A.C.Sousa 20; (d, e) not collected; (f) A.A.C. Sousa 15. 

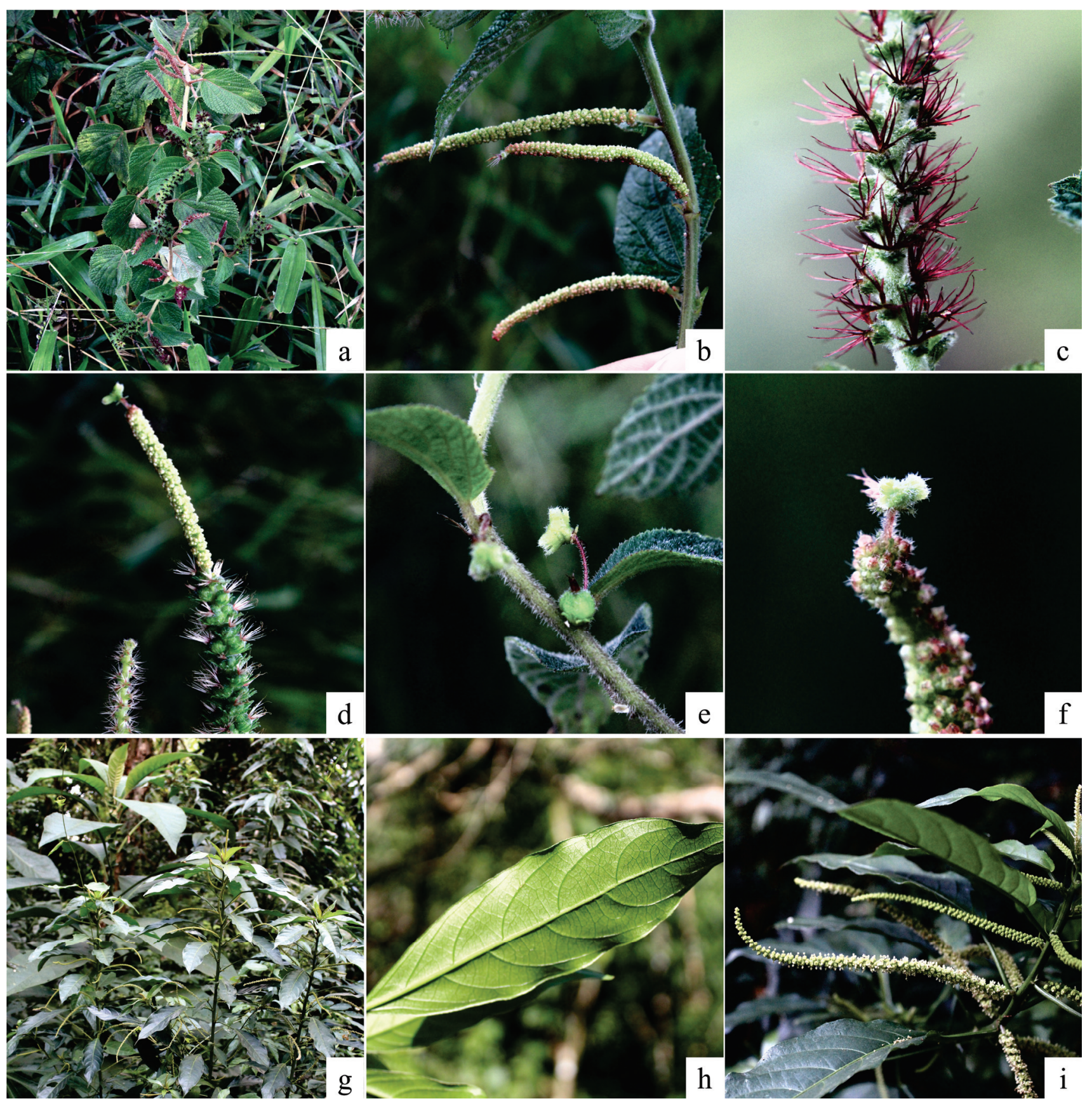

Figura 3. a-f. Acalypha communis. a. Hábito. b. Inflorescência estaminada. c. Inflorescência pistilada. d. Inflorescência bissexual [rara] com flor alomórfica no ápice. e-f. Flores alomórficas. g-i. A. digynostachya. g. Hábito. h. Detalhe da folha evidenciando as margens inconspicuamente serrilhadas. i. Inflorescências estaminadas. Fotos: (a, i) O.L.M. Silva. Vouchers: (a, f): A.A.C. Sousa 15; (g, i): O.L.M. Silva 302.

Figure 3. a-f. Acalypha communis. a. Habit. b. Staminate inflorescence. c. Pistillate inflorescence. d. Bisexual inflorescence [rare] with allomorphic flower at the apex. e-f. Allomorphic flowers. g-i. A. digynostachya. g. Shrub. h. detail of the leaf showing inconspicuously serrated margins. i. Staminate inflorescences. Photos: (a, i) O.L.M. Silva. Vouchers: (a, f): A.A.C. Sousa 15; (g, i): O.L.M. Silva 302. 
Acalypha diversifolia Jacq. P1. Hort. Schoenbr. 2: 63, pl. 244. 1797. Tipo: VENEZUELA. "ex Caracas", Tab. 244 in Jacq., P1. Hort. Schoenbr. 2, 1797 (lectótipo, designado por Cardiel [1995b: 233]).

Acalypha diversifolia é uma espécie de hábito arbustivo a arbóreo. Suas folhas são discolores e com margem serreada. As inflorescências unissexuais ou bissexuais são sempre axilares, sendo as espigas estaminadas curtas (quando comparada com as demais espécies do gênero ocorrentes no estado) e congestas. A espécie é semelhante a $A$. digynostachya, mas difere-se desta última pela morfologia foliar (folhas discolores com margem serreada em $A$. diversifolia vs folhas concolores com margem inteira a ligeiramente crenada em A. digynostachya).

Espécie amplamente distribuída nos neotrópicos. No Brasil ocorre nas regiões Nordeste (BA), Norte (AC, RO e RR), Centro-Oeste (GO e MT) e Sudeste (MG e SP). É frequentemente encontrada em solos argilosos, aparentemente típica de vegetação de cerrado.

Material selecionado: BRASIL. São PAULo: Pereira Barreto, 11-VII-1985, F. Barros 1204 (SP).

Acalypha gracilis Spreng. Syst. Veg. 4(2): 315. 1827. Tipo: BRASIL. F. Sellow [Sello] s.n. (neótipo W [W167581!], designado por Cardiel \& Muñoz-Rodríguez [2015: 395]; isoneótipos $\mathrm{W}$ !, $\mathrm{B} \dagger$ ).

Figuras $4 \mathrm{c}-\mathrm{f}$

Acalypha gracilis apresenta hábito arbustivo e inflorescências unissexuais, sendo as estaminadas terminais e axilares, e as pistiladas somente axilares ou subterminais. As brácteas das flores pistiladas são eretas e profundamente laciniadas. A espécie é semelhante a $A$. digynostachya, da qual pode ser diferenciada por características vegetativas (ver comentários em A. digynostachya).

É uma espécie típica da Floresta Atlântica, ocorrendo em florestas ombrófilas e locais sombreados. A espécie ocorre no Brasil, Paraguai e Uruguai (Cardiel \& Muñoz-Rodríguez 2015). No Brasil ocorre nas regiões Sudeste (MG, RJ e SP) e Sul (PR e SC).

Material selecionado: BRASIL. SÃo PAULo: São José do Barreiro, 19-I-2013, O.L.M. Silva et al. 69 (SP).

Acalypha herzogiana Pax \& K. Hoffm. Meded. Rijks-Herb. 40: 24. 1921. Tipo: BOLIVIA. "im Walde zwischen Rio Pirai und Rio Cuchi”, 450 m., T. Herzog 1453 (lectótipo S [S-R-7754!], designado por Cardiel et al. [2013b: 159]; isolectótipos $\mathrm{B} \uparrow[\mathrm{B}$ neg. F-5294!], Z!).
Acalypha herzogiana é a única espécie ocorrente no Estado de São Paulo que apresenta hábito herbáceo ou subarbustivo. Suas inflorescências são unissexuais, sendo as estaminadas longas e terminais e as pistiladas axilares e congestas. As flores pistiladas apresentam longos estiletes, totalmente laciniados e rubros. A espécie é semelhante a A. multicaulis, porém $A$. herzogiana é pouco ramificada, possui uma longa e delicada inflorescência estaminada terminal e a bráctea pistilada é orbicular e diminuta, enquanto $A$. multicaulis é ramificada desde a base, as inflorescências estaminadas terminais são mais curtas e robustas e a bráctea pistilada é maior e orbicular.

A espécie ocorre na Argentina, Bolívia, Brasil e Paraguai (Cardiel \& Muñoz-Rodríguez 2015). No Brasil há apenas registro de ocorrência para os Estados de São Paulo e Rio de Janeiro.

Estudos recentes de Steinmann \& Levin (2011), com base na filogenia proposta por Sagun et al. (2010), concluíram que a planta cultivada e conhecida em horticultura como Acalypha reptans, trata-se de fato da $A$. herzogiana. As diferenças morfológicas entre as plantas cultivadas e a $A$. herzogiana encontrada na natureza, seriam explicadas pelo processo de seleção e melhoramento do cultivo. É encontrada em cultivo em todas as regiões brasileiras e difere da forma nativa pelo crescimento prostrado, pelas inflorescências pistiladas muito evidentes em racemos longos e terminais, com estiletes muito ramificados e vermelhos.

Material selecionado: BRASIL. São PAULO. Cabeceira do Rio Feio, Fazenda Faca, VI-1905, Edwall s.n. (SP 13760).

Acalypha macrostachya Jacq. P1. Hort. Schoenbr. 2: 63, pl. 245. 1797. Tipo: VENEZUELA. "crescit ad Caracas"; Tab. 245 in Jacq., P1. Hort. Schoenbr. 2, 1797 (lectótipo, designado por Cardiel [1995b:233]).

Acalypha macrostachya é uma espécie monoica com inflorescências unissexuais. Suas folhas são levemente cartáceas, ovais a reniformes, sempre maiores que $12 \mathrm{~cm}$ de comprimento, com nervuras primárias e secundárias muito proeminentes. As inflorescências pistiladas e estaminadas são muito longas, com até $40 \mathrm{~cm}$ de comprimento. Difere das demais espécies de Acalypha ocorrentes na área de estudo, pelos pecíolos e folhas extremamente grandes e robustos, além das folhas cartáceas.

Na região Neotropical, está distribuída desde o México, América Central e Caribe até Bolívia, Brasil, 

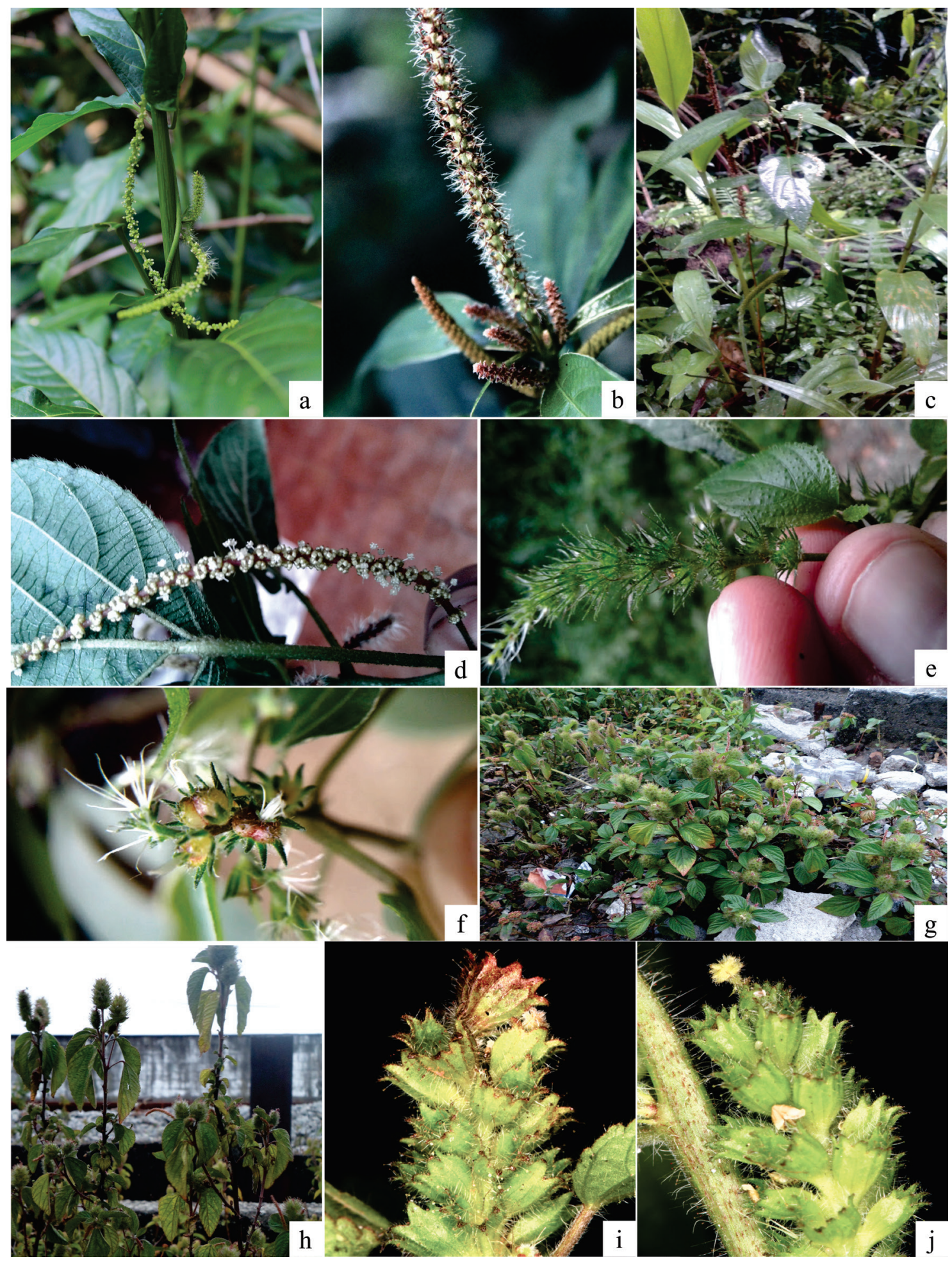

Figura 4. a-b. Acalypha digynostachya. a-b. Inflorescências pistiladas e estaminadas [b. Inflorescência subterminal]. c-f. A. gracilis. c. Hábito. d. Inflorescência estaminada. e. Inflorescência pistilada. f. frutos. g-j. A. poiretii: g-h. Hábito. i. Inflorescência pistilada. j. Inflorescência pistilada com flor alomórfica no ápice. Fotos: (a, b, i, j ) O.L.M. Silva; (c, d, e, f, g, h) A.A.C. Sousa. Vouchers: (a, b, ) O.L.M. Silva 302; (c, d, e) A.A.C. Sousa 9; (f) A.A.C. Sousa 14; (g, h) A.A.C. Sousa 6; (i, j) A.A.C. Sousa, 17.

Figure 4. a-b. Acalypha digynostachya. a-b. Pistillate and staminate inflorencences [b. Subterminal inflorescence]. c-e. A. gracilis. c. Habit. d. Staminate inflorescence. e. Pistillate inflorescence. f. Fruits. g-j. A. poiretii. g-h. Habit. i. Pistillate inflorencence. j. Pistillate inflorescence with an allomorphic flower at the apex. Photos: (a, b,i, j) O.L.M. Silva; (c, d, e, f, g, h) A.A.C. Sousa. Vouchers: (a, b) O.L.M. Silva 302; (c, d, e) A.A.C. Sousa 9; (f) A.A.C. Sousa, 14; (g, h) A.A.C. Sousa 6; (i, j) A.A.C. Sousa 17. 
Colômbia, Equador, Peru e Venezuela (Cardiel et al. 2016, Pax \& Hoffman 1924). No Brasil, ocorre nas regiões Norte (AM e RR) e Sudeste (MG e SP). Sua provável distribuição disjunta no Brasil, pode ser resultado da falta de estudos sobre o gênero ou pela falta de coleta e identificação de seus espécimes nos herbários.

Material selecionado: BRASIL. São PAULO: São João da Boa Vista, 12-XI-1947, M. Kuhlmann 1481 (SP).

Material adicional selecionado: BOLÍVIA. SANTA CruZ: Província de Ichilo, 20-X-1999, M. Nee 50245 (SP).

Acalypha multicaulis Müll.Arg. Linnaea 34: 53. 1865. Tipo: BRASIL. F. Sellow s.n. (neótipo K!, designado por Cardiel et al. [2013b:163]).

Nome popular: canela-de-nambu.

Acalypha multicaulis é um subarbusto subereto de crescimento subterrâneo conspícuo, com ramos até $20 \mathrm{~cm}$ de altura, com folhas congestas. São plantas monoicas, com folhas pequenas, nunca ultrapassando $2,5 \mathrm{~cm}$ de comprimento. As inflorescências são axilares e terminais, unissexuais ou bissexuais, sendo as flores pistiladas às vezes solitárias e axilares ao longo do ramo. A espécie é morfologicamente semelhante a Acalypha amblyodonta e A. herzogiana, das quais pode ser diferenciada por diversas características vegetativas e reprodutivas (ver comentários em $A$. amblyodonta e $A$. herzogiana).

Espécie típica de cerrado. Ocorre no Argentina, Bolívia, Brasil, Paraguai e Uruguai (Cardiel \& Muñoz-Rodríguez 2015). No Brasil é registrada para as regiões Nordeste (BA, CE e SE) e Sudeste (MG, RJ e SP).

Material selecionado: BRASIL. São PAUlo: Promissão, 20-VI-1939, G. Hashimoto s.n. (SP 41283).

Acalypha poiretii Spreng. Syst. Veg. 3: 879. 1826.

Tipo: “Amer. trop.", Anonymous s.n. (holótipo P-LAM [P00382110!]).

Figura 4 g-j

Nome popular: chorão.

Acalypha poiretii é uma planta anual, comumente encontrada em solos arenosos. Suas inflorescências são bissexuais ou unissexuais, terminais e axilares, conspicuamente pedunculadas, densamente bracteadas, o que confere um formato cilíndrico à espiga. Nas inflorescências bissexuais que são sempre terminais, a região estaminada encontra-se na porção distal e é bem menor em relação à pistilada. As inflorescências unissexuais são geralmente axilares e densamente congestas. As inflorescências pistiladas terminais e densamente bracteadas de Acalypha poiretii são semelhantes às de Acalypha communis, porém diferem pelas brácteas denteadas em Acalypha poiretii ( $v s$ brácteas profundamente laciniadas em Acalypha communis).

Acalypha poiretii é amplamente distribuída nas Américas, principalmente em áreas perturbadas, e pode ser considerada potencialmente ruderal. É uma espécie típica de vegetação aberta. No Brasil, ocorre nas regiões Nordeste (BA, CE e PE), Centro-Oeste (DF) e Sudeste (MG, RJ e SP).

Material selecionado: BRASIL. São PAULo: São Paulo, Bairro da Lapa, Estação Ferroviária da LAPA. 12-VI-2013, A.A.C. SousA 6 (SP).

Acalypha velamea Baill. Adansonia 5: 228, 1865. Tipo: BRASIL. Mato Grosso: C. GaudichaudBeaupré 246 (holótipo P [P000645427]!).

Acalypha velamea, assim como A. communis, possui inflorescências pistiladas terminais e estaminadas axilares. No entanto, as duas espécies podem ser distintas pelo hábito e folhas (hábito subarbustivo e folhas sésseis à subsésseis em $A$. velamea vs hábito predominantemente arbustivo e folhas pecioladas em A. communis). Além disso, $A$. velamea sempre apresenta um denso indumento velutino a tomentoso, enquanto que $A$. communis apresenta indumento que varia de pubescente, hirsuto a glabrescente.

A espécie ocorre na Argentina, Brasil e Paraguai (Cardiel \& Muñoz-Rodríguez 2015). No Brasil é encontrada em vegetação de cerrado, nas regiões Centro-Oeste (MT e GO) e Sudeste (SP).

Material selecionado: BRASIL. São PAUlo: MogiGuaçu, Fazenda Campininha, 17-XI-1980, A. Custódio Filho 400 (SP).

Acalypha villosa Jacq. Enum. Syst. P1. 32. 1760. Tipo: COLOMBIA. "HabitatCarthagenae in silvis \& sepibus", Tab. 183, fig. 16. in Jacquin, Select. Stirp. Amer. Hist., 1763 (lectótipo, designado por R. A. Howard \& A. J. Bornstein [1989: 10]; epítipo, Tab. 47 in Jacquin, Hort. Bon. Vindov. 3. 1776, designado por Cardiel 1995b: 232).

Acalypha villosa é um arbusto monoico ou dioico, com inflorescências geralmente unissexuais, 
inflorescências pistiladas laxas racemosas ou raramente paniculadas. Difere das demais espécies ocorrentes em São Paulo por apresentar flores pistiladas pediceladas e pelo cálice 5-lobado e pelas brácteas não acrescentes no fruto. As demais espécies de Acalypha citadas para o Estado de São Paulo apresentam bráctea acrescente no fruto, cálice 3-lobado e flores pistiladas sésseis.

A espécie é amplamente distribuída do México até o norte da Argentina (Muñoz-Rodrígiuez et al. 2014). No Brasil, ocorre no Centro Oeste (GO, MT e MS), Nordeste (BA e CE), Norte (RO) e Sudeste (MG e SP).

Material selecionado: BRASIL. São PAULO: Matão, s.d., J.C. Teixeira 387 (SP).

\section{Considerações sobre Acalypha no Estado de São Paulo}

É importante ressaltar que apesar de nenhuma espécie do gênero ter sido citada na "Lista oficial das espécies da Flora de São Paulo ameaçadas de extinção" (Secretaria do Meio Ambiente do Estado de São Paulo 2016), de acordo com os critérios de Mamede et al. (2007), Acalypha claussenii, A. multicaulis e A. herzogiana podem ser consideradas na categoria Presumivelmente Extinta (EX) no Estado de São Paulo, uma vez que as espécies possuem coletas datadas dos anos 1821, 1939 e 1905, respectivamente, não tendo sido mais coletadas no Estado nos últimos 50 anos.

De acordo com os dados obtidos neste trabalho, Acalypha é o terceiro gênero mais numeroso da família Euphorbiaceae no Estado de São Paulo, com 14 espécies, estando atrás apenas de Croton (com 38 espécies, segundo Caruzo \& Santos 2015) e Euphorbia (com 24 espécies, segundo Silva et al. 2016), o que demonstra a sua importância na flora paulista.

\section{Agradecimentos}

À Fundação de Amparo à Pesquisa do Estado de São Paulo (FAPESP) pela bolsa concedida a primeira autora (processo 2012/200255). Ao O.L.M. Silva pelas fotos concedidas. Aos curadores dos herbários e pesquisadores das demais instituições visitadas pela contribuição.

\section{Literatura citada}

BFG (The Brazilian Flora Group). 2015. Growing knowledge: an overview of Seed Plant diversity in Brazil. Rodriguésia 66: 1085-1113.
Cardiel, J.M. 1994. Revisión taxonómica del género Acalypha L. (Euphorbiaceae) en Colombia. Tesis Doctoral. Universidad Complutense de Madrid.

Cardiel, J.M. 1995a. Acalypha (Euphorbiaceae). Flora de Colombia. Monografía n 15. Universidad Nacional de Colombia y Real Jardín Botánico de Madrid C.S.I.C. pp. 1-155.

Cardiel, J.M. 1995b. Tipificación de las especies de Acalypha L. (Euphorbiaceae) descritas por Jacquin. Anales del Jardín Botánico de Madrid 54: 230-233.

Cardiel, J.M. 2015. Acalypha in Lista de Espécies da Flora do Brasil. Jardim Botânico do Rio de Janeiro. Disponível em http://floradobrasil.jbrj.gov.br/jabot/ floradobrasil/FB17439 (acesso em 22-XII-2016).

Cardiel, J.M. \& Muñoz-Rodríguez, P. 2012a. Synopsis of Acalypha (Euphorbiaceae) of continental Ecuador. PhytoKeys 17: 1-17.

Cardiel, J.M. \& Muñoz-Rodríguez, P. 2012b. Two new species of Acalypha (Euphorbiaceae) from Bolivia. Brittonia 64: 363-367.

Cardiel, J.M. \& Muñoz-Rodríguez, P. 2013. Acalypha carrascoana Cardiel (Euphorbiaceae) novelty for the flora of Mexico. Botanica Complutensis 37: 53-56.

Cardiel, J.M. \& Muñoz-Rodríguez, P. 2015. Synopsis of Acalypha (Euphorbiaceae) of Argentina, Paraguay and Uruguay. Annals of the Missouri Botanical Garden 101: 384-405.

Cardiel, J.M., Dorda, E., Muñoz, P., Santayana, M.P. 2016. Acalypha Taxonomic Information System. Disponível em http://www.acalypha.es/ (acesso em 22-XII-2016).

Cardiel, J.M., Muñoz-Rodríguez, P. \& MuñozGarmendia, F. 2013. Revised taxonomy and nomenclature of Acalypha sect. Communes (Euphorbiaceae), a complex group of species widespread in the north of Southern Cone. Taxon 62: 1296-1304.

Cardiel, J.M., Nee, M. \& Muñoz-Rodríguez, P. 2014. Synopsis of Acalypha (Euphorbiaceae) of Peru and Bolivia, with description of a new species. Anales del Jardín Botánico de Madrid 70: 152-177.

Carneiro, D.S., Cordeiro, I. \& França, F. 2002. A família Euphorbiaceae na flora de inselbergs da região de Milagres, Bahia, Brasil. Boletim de Botânica da Universidade de São Paulo 20: 31-47.

Caruzo, M.B.R., \& Santos, R.F. 2015. First record of Croton echinocarpus (Euphorbiaceae: Crotoneae) in São Paulo state, Brazil. Check List 11: 1684.

Cordeiro, I. 2004. Flora de Grão-Mogol, Minas Gerais: Euphorbiaceae. Boletim de Botânica da Universidade de São Paulo 22: 109-131.

Gordillo, M.M., Ramíréz, J.J., Durán, R.C., Arriaga, E.J., Garcia, R., Cervantes, A., Hernández, R.M. 2002. Los géneros de la Família Euphorbiaceae em México. Anales del Instituto de Biología, Universidad Nacional Autónoma de México, Série Botánica 73: $155-281$. 
Govaerts, R., Frodin, D.G. \& Radcliffe-Smith, A. 2000. World Checklist and Bibliography of Euphorbiaceae (and Pandaceae). Kew Royal Botanical Gardens 1: 47-109.

Levin, G.A., Steinmann, V.W., Sagun, V.G. 2005. Phylogeny and biogeography of Acalypha (Abstract). Abstracts of the XVII International Botanical Congress: 68. Vienna, Áustria.

Linnaeus, C. 1753. Species Plantarum. ed. 2. Laurent Salvi, Stockholm.

Mamede, M.C., Souza, V.C., Prado, J. Barros, F., Wanderley, M.G.L. \& Rando, J.G. 2007. Livro Vermelho das Espécies Vegetais Ameaçadas do Estado de São Paulo. Instituto de Botânica de São Paulo, São Paulo, pp. 1-165.

Müller Argoviensis, J. 1874. Euphorbiaceae. In: C.F.P. Martius, A.G. Eichler (eds.). Flora Brasiliensis 11: 338-369.

Muñoz-Rodríguez, P., Cardiel, J.M. \& Atha, D. 2014. Acalypha subgenus Linostachys (Euphorbiaceae, Acalyphoideae): a global review. Phytotaxa 166: 199-221.

Pax, F. \& Hoffmann, K. 1924. EuphorbiaceaeCrotonoideae-Acalypheae-Acalyphinae, Additamentum VII. In: A. Engler (ed.). Das Pflanzenreich IV.147. xvi (Heft 85). Engelmann, Leipzig.

Radcliffe-Smith A. 2001. Genera Euphorbiacearum. Royal Botanic Garden, Kew, Richmond, pp 455.

Sagun, V.G., Levin, G.A. \& Welzen, P.C. van. 2010. Revision and phylogeny of Acalypha (Euphorbiaceae) in Malesia. Blumea 55: 21-60.

Secretaria do Meio Ambiente do Estado de São Paulo. 2016. Resolução SMA-57, de 05-VI-2016. Lista de espécies da flora ameaçadas de extinção no estado de São Paulo. Diário Oficial do Estado de São Paulo, Poder Executivo, São Paulo, 07-VI-2016. Seção I, v. 126, n. 103, pp. 69-71.
Silva, O.L.M., Cordeiro, I. \& Caruzo, M.B.R. 2016. Seed morphology in Euphorbia and its applications: a case study in São Paulo, Brazil. Brazilian Journal of Botany 39: 349-358.

Steinmann, V.W., Levin, G.A. 2011. Acalypha herzogiana (Euphorbiaceae), the correct name for an intriguing and commonly cultivated species. Brittonia 63: 500-504.

Thiers, B. (continuamente atualizado). 2016. Index Herbariorum: A global directory of public herbaria and associated staff. New York Botanical Garden's Virtual Herbarium. The New York Botanical garden, newYork. Disponível em http:// sweetgum.nybg.org/ih/ (acesso em 20-XII-2016).

Wanderley, M.G.L., Shepherd, G.J., Melhem, T.S., Giulietti, A.M. \& Martins, S.E. 2009. Flora Fanerogâmica do Estado de São Paulo. v. 4. São Paulo, Instituto de Botânica. pp. XIX-XXIII.

Wanderley, M.G.L., Shepherd, G.J., Martins, S.E., Estrada, T.E.M.D., Romanini, R.P., Koch, I., Pirani, J.R., Melhem, T.S., Harley, A.M G., Kinoshita, L.S., Magenta, M.A.G., Wagner, H.M.L., Barros, F., Lohmann, L.G., Amaral, M.C.E., Cordeiro, I., Aragaki, S., Bianchini, R.S. \& Esteves, G.L. 2011. Checklist of Spermatophyta of the São Paulo State, Brazil. Biota Neotropica 11: 194-390.

Webster, G.L. 1994. Systematics of the Euphorbiaceae. Annals of the Missouri Botanical Garden 81: 1-144.

Wurdack, K.J., Hoffmann, P. \& Chase, M.W. 2005. Molecular phylogenetics analysis of uniovulate Euphorbiaceae (Euphorbiaceae sensu stricto) using plastid $\mathrm{rbcL}$ and $t r n L-F$ DNA sequences. American Journal of Botany 92: 1397-1420.

Wurdack, K.J. \& Davis, C.C. 2009. Malpighiales Phylogenetics: Gaining ground on one of the most recalcitrant clades in the angiosperm tree of life. American Journal of Botany 96: 1551-1570. 